\title{
A FRAGILIDADE AMBIENTAL DO AQUÍFERO SERRA GERAL NA SUB-BACIA HIDROGRÁFICA DO ALTO URUGUAI-BRASIL
}

\author{
the environmental fragility in Serra Seral aquifer in Alto Uruguai hydrographic basin in Brazil
}

\author{
Andrea Valli Nummer* \\ Vinícius Duarte Guareschi** \\ Dionísio Saccol Sangói***
}

\begin{abstract}
Resumo
O objetivo deste trabalho é apresentar uma proposta metodológica para avaliar a fragilidade ambiental do Aquífero Serra Geral na Sub-Bacia Hidrográfica do Alto Uruguai, comparando os resultados com aqueles obtidos pelo projeto " Desenvolvimento Metodológico e Tecnológico para Avaliação Ambiental Integrada Aplicada ao Processo de Análise de Viabilidade de Hidrelétricas", denominado "Frag-Rio". Os procedimentos metodológicos incluíram a extração e identificação das intersecções dos lineamentos em imagens SRTM utilizando SIG's. A metodologia adotada mostrou-se eficaz identificando áreas frágeis junto as calhas dos rios, no noroeste e norte da sub-bacia. Na escala de trabalho adotada, as áreas de fragilidade elevada são equivalentes considerando-se ambas as metodologias. As vantagens da metodologia desenvolvida em relação a do Frag-Rio incluem a discriminação de áreas com fragilidade elevada dispersas pela sub-bacia e a facilidade de acesso as imagens SRTM.
\end{abstract}

Palavras-chave: Águas Subterrâneas, Aquífero Serra Geral, Lineamentos, Projeto Frag-Rio, Bacia Hidrográfica.

\begin{abstract}
The objective of this paper is to present a methodological proposition in order to evaluate the environmental fragility of the Serra Geral Aquifer in the Sub-Basin of the Upper Uruguay comparing the results with those obtained by the project "Methodological and Technological Development for Integrated Environmental Assessment Applied to the Process of Analyses of Hydropower Feasibility, "called" Frag-Rio." The methodological procedures included the extraction and identification of the intersections of lineaments in the SRTM images using GIS. The methodology adopted proved to be effective at identifying vulnerable areas to natural flow of rivers in the northwest and northern sub-basin. On the scale of work adopted, the areas of high vulnerability are equivalent considering both approaches. The advantages of the methodology developed in relation to the Frag-Rio include the discrimination of areas with high fragility scattered by the sub-basin and the easy access to SRTM images.
\end{abstract}

Key words: Underground Waters, Serra Geral Aquifer, Lineaments, Project Frag-Rio, Hydrographic Basin.

\section{Resumen}

El presente trabajo tuvo como objetivo presentar una propuesta metodológica para evaluar la fragilidad ambiental del Acuífero Serra Geral en la Sub-Cuenca Hidrográfica del Alto Uruguay comparando los resultados con aquellos obtidos por el proyecto " Desarrollo Metodológico y Tecnológico para Evaluación Ambiental Integrada Aplicada al Proceso de Análisis de Viabilidad de Hidrelétricas", llamado "Frag-Rio". Los procedimientos metodológicos abarcaron la extración y identificación de las interseciones de los lineamientos en imágenes SRTM usando SIG's. La metodología adoptada se mostró satisfatoria identificando áreas frágiles junto a las callas de los ríos, en el noroeste y norte de la sub-cuenca. En el cómputo del trabajo adoptado, las áreas de fragilidad elevada son equivalentes contemplando las metodologías. Las ventajas de la metodología desarrollada en relación a del Frag-Rio abarca la discriminación de las áreas con fragilidad elevada desparramda por la sub-cuenca y la facilidad del acceso a las imágens SRTM 1.

Palabras clave: Águas subterráneas, Acuífero Serra Geral, Lineamientos, Proyecto Frag-Rio, Cuenca Hidrográfica.

(*) Prof ${ }^{\mathrm{a}}$. Dr ${ }^{\mathrm{a}}$. da Pós-Graduação em Geografia- da Universidade Federal de Santa Maria - Cid. Univ., Av. Roraima n ${ }^{\circ} 1000$, CEP 97105-900, Camobi-Santa Maria (RS), Brasil, Tel:(+ 55 55) 32209446 - a.nummer@gmail.com

(**) Mestrando do Programa de Pós-Graduação em Geografia da Federal de Santa Maria - Cid. Univ., Av. Roraima ${ }^{\circ} 1000$, CEP 97105-900, Camobi-Santa Maria (RS), Brasil, Tel: (+ 5555 ) 32209446 - vdguareschi@yahoo.com.br

(***) Mestre pelo do Programa de Pós-Graduação em Geografia da Federal de Santa Maria - Cid. Univ., Av. Roraima ${ }^{\circ} 1000$, CEP 97105-900, Camobi-Santa Maria (RS), Brasil, Tel: (+ 5555 ) 32209446 - dionisiosangoi@gmail.com 


\section{INTRODUÇÃO}

O crescimento demográfico brasileiro associado às transformações no perfil econômico do país como consequência do aumento dos processos de urbanização, industrialização e expansão agrícola, intensificados a partir da década de 1960, passaram a exigir constantes investimentos no setor energético nacional.

No Brasil, a utilização dos recursos hídricos para gerar energia elétrica tem se constituído num dos principais vetores da matriz energética, acarretando a construção de usinas hidrelétricas como grandes empreendimentos técnicos e econômicos (MARQUES, 2005).

A geração hidráulica é responsável por cerca de $40 \%$ da oferta interna de energia do país. De acordo com o Ministério de Minas e Energia (MME), entre janeiro de 2003 a outubro de 2010, foram acrescentados 28.561,9 MW de potência instalada em todo o território nacional, sendo 12.083,9 MW provenientes de hidrelétricas. Atualmente, estão em operação 866 usinas hidrelétricas, responsáveis por $67,2 \%$ da matriz de energia elétrica do Brasil.

Esta preferência nacional pelas hidrelétricas justifica-se pelo potencial hídrico que o país apresenta, dispondo da rede hidrográfica mais extensa do planeta com predomínio de rios de planalto. No entanto, esta modalidade de geração de energia considerada renovável, não poluente e de baixo custo, enfrenta críticas de alguns segmentos da sociedade diante dos problemas de escassez da qualidade e quantidade da água, o que torna necessário uma abordagem multidisciplinar na elaboração de projetos no sentido de selecionar as melhores áreas para a construção das usinas hidrelétricas a fim de minimizar os impactos socioambientais decorrentes da instalação desses empreendimentos.

Estudos sobre a fragilidade ambiental relacionados à viabilidade de instalação de hidrelétricas estão sendo desenvolvidos no projeto intitulado: "Desenvolvimento Metodológico e Tecnológico para Avaliação Ambiental Integrada Aplicada ao Processo de Análise de Viabilidade de Hidrelétricas", denominado "Projeto Frag-Rio", com início no ano de 2009 e ainda em andamento, realizado em parceria com o Ministério do Meio Ambiente (MMA) e pesquisadores das Universidades Federal do Pampa - Unipampa - e Federal de Santa Maria - UFSM, ambas no Estado do Rio Grande do Sul, a fim de selecionar as áreas mais aptas para a implantação de barragens.

Este projeto atende as necessidades do MMA de realização de Avaliação Ambiental Integrada de Bacias Hidrográficas como estratégia para minimizar os diversos conflitos que vinham eclodindo nos licenciamentos dos empreendimentos hidrelétricos.

A Primeira Etapa do Projeto Frag-Rio foi desenvolvida na sub-bacia hidrográfica do Alto Uruguai (Estados do Rio Grande do Sul e Santa Catarina), onde foram considerados, para Análise Ambiental Integrada (AAI), tanto aspectos do meio físico, como do biótico e do antrópico. Uma das variáveis do meio físico, analisada no projeto Frag-Rio, é a que diz respeito à água subterrânea, pois a água dos lagos formados pela usinas hidrelétricas podem transportar substâncias potencialmente poluidoras para os aqüíferos.

A metodologia utilizada para avaliação da fragilidade da água subterrânea no Projeto Frag-Rio baseou-se em uma combinação de variáveis como espessura da zona vadosa, superfície potenciométrica e buffers de incremento de fragilidade ao redor de fraturas e de poços de água mineral.

As águas subterrâneas distribuem-se verticalmente no subsolo através da zona insaturada, conhecida como zona vadosa ou de aeração e da zona saturada. A zona insaturada consiste de interstícios parcialmente ocupados por água e parcialmente por ar (MANOEL FILHO, 2008). A espessura da zona vadosa é obtida entre a cota altimétrica da superfície do terreno até o nível da água e quanto menor o seu valor, mais frágil será o meio em relação a sua capacidade natural de absorver e/ou diluir uma carga contaminante imposta na superfície do terreno. 
Já a superfície potenciométrica é a relação entre a cota altimétrica da boca do poço e o nível da água e indica uma carga hidráulica sobre um datum (CABRAL, 2008), que neste caso é o nível zero ou Nível do Mar (Oceano Atlântico). A superfície potenciométrica também indica a direção do fluxo subterrâneo, portanto se houver contaminantes oriundos da superfície do terreno (carga antrópica poluente), ela seguirá esta tendência.

Ao serem apresentados os resultados do Projeto Frag-Rio aos técnicos dos diferentes Órgãos de Licenciamento Ambiental, críticas ocorreram quanto ao uso da metodologia adotada para a avaliação da fragilidade da água subterrânea, uma vez que o procedimento utilizado seria mais adequado para aquíferos porosos e não os do tipo fissural predominantes na maior parte da sub-bacia. Grande parte da sub-bacia do Alto Uruguai encontra-se sobre rochas vulcânicas da Formação Serra Geral, configurando um aquífero do tipo fissural ou fraturado conhecido como Aquifero Serra Geral, que apresenta comportamento hidrodinâmico muito heterogêneo.

Os aqüíferos porosos ou intergranulares são constituídos por rochas sedimentares e apresentam elevada porosidade cuja dimensão é da ordem milimétrica ou micrométrica capaz de absorver, armazenar e transmitir água no seu interior. Já os aqüíferos do tipo fissural ocorrem em rochas compactas e se desenvolvem através de falhas, fraturas ou descontinuidades no maciço rochoso que constituem aberturas pelas quais a água infiltrada é armazenada e flui (COSTA,2008).

O presente artigo tem a finalidade de apresentar os procedimentos metodológicos desenvolvidos para avaliação da fragilidade da água subterrânea em aquíferos fraturados com base na densidade de lineamentos morfo-estruturais, procurando comparar os resultados obtidos com aqueles provenientes da metodologia adotada no Frag-Rio.

\section{CARACTERIZAÇÃO DA ÁREA DE ESTUDO}

A Bacia Hidrográfica do Rio Uruguai abrange uma área de aproximadamente $384.000 \mathrm{~km}^{2}$, dos quais $176.000 \mathrm{~km}^{2}$ situam-se em território brasileiro (ANEEL, 1998). Desse total, $73 \%$ está situado no estado do Rio Grande do Sul e 27\% no estado de Santa Catarina. Esta Bacia foi dividida em quatro (4), sub-bacias, devido a sua extensão e à diversidade paisagística, conforme o estabelecido no Plano Nacional de Recursos Hídricos (PNRH - Resolução No 32). As sub-bacias são: 1) do Alto Uruguai; 2) do Uruguai Médio; 3) do Rio Ibicuí; 4) do Rio Negro (Figura 1).

A sub-bacia hidrográfica do Alto Uruguai (Figura 2), área deste estudo, apresenta um clima do tipo "cfa" com pequenas variações para "cfb"de acordo com a classificação de Koppen. O primeiro indica clima temperado chuvoso de ambiente úmido e o segundo, considerado frio, ocorre nas regiões mais elevadas das serras, com temperatura média anual inferior a $18^{\circ} \mathrm{C}$ e a média do mês mais quente situando-se entre $18^{\circ} \mathrm{C}$ e $22^{\circ} \mathrm{C}$. As chuvas apresentam distribuição regular durante todo o ano, com precipitação média anual variando entre $1250 \mathrm{~mm}$ a 2100mm (NIMMER, 1989).

Em relação às características Geológicas e Geomorfológicas, a sub-bacia do Alto Uruguai está inserida dentro dos domínios das bacias e coberturas sedimentares, correspondendo à Província Sedimentar do Paraná (RADAMBRASIL,1986). Predominam na área as rochas vulcânicas básicas e intermediárias da Formação Serra Geral e subordinadamente as rochas ácidas, que concentram-se na porção sudeste e norte-noroeste da sub-bacia. Ao sul da área e sobre a Formação Serra Geral ocorrem os arenitos friáveis da Formação Tupanciretã. A maior variabilidade de rochas ocorre de forma localizada em Santa Catarina, na região do Domo de Lages (no entorno do Município de Lajes). Nesta região ocorre uma grande variedade de rochas sedimentares como quartzo-arenitos, siltitos, calcários, folhelhos e diamictitos, Os aluviões e os depósitos colúvio/aluvionares ocorrem nas calhas dos rios e em seu entorno. 

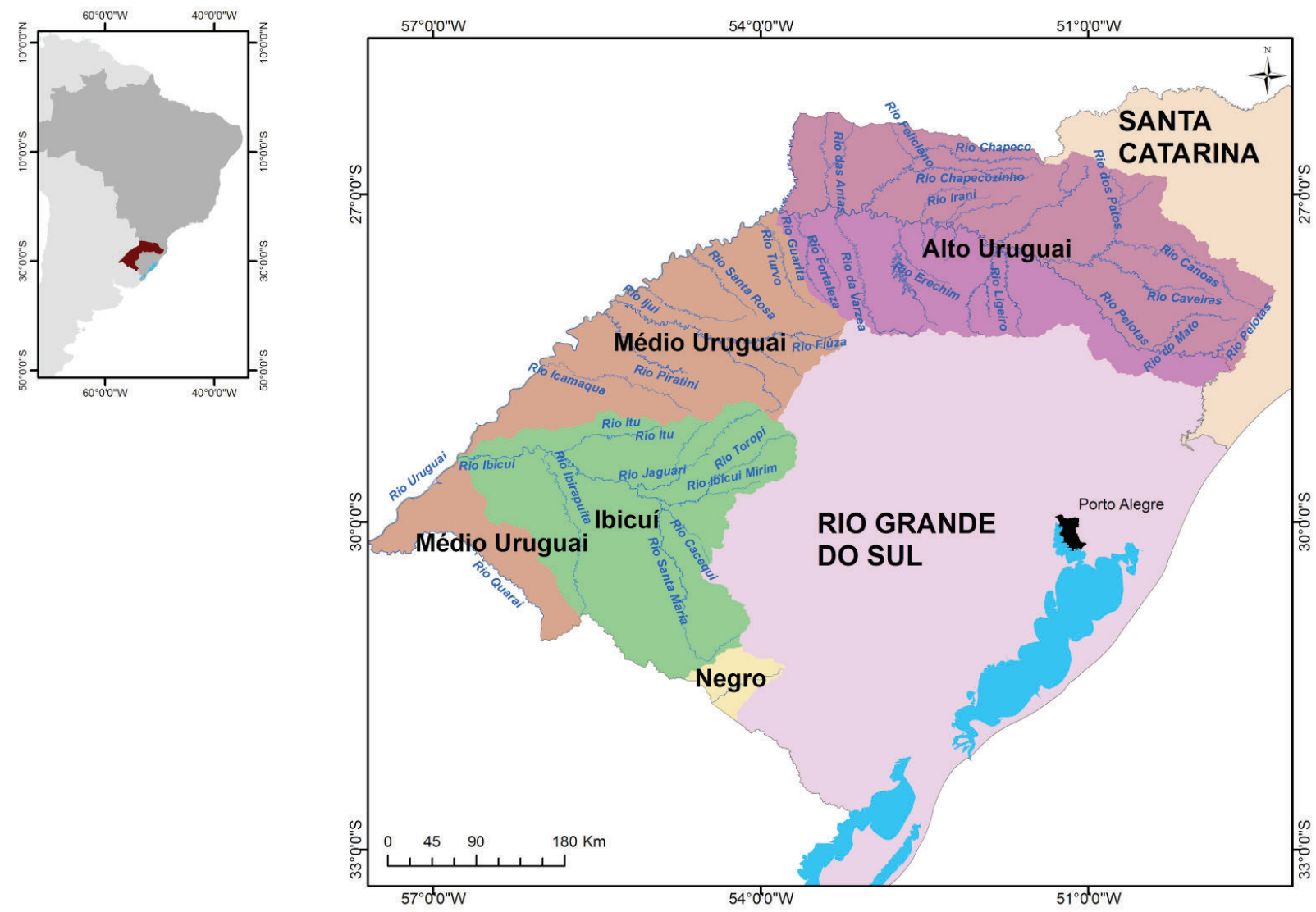

Figura 1 - Localização da Bacia Hidrográfica do Uruguai e suas sub-bacias.

$\mathrm{Na}$ Sub-Bacia, tanto as estruturas tectônicas frágeis como falhas e fraturas, quanto às estruturas atectônicas, como contatos entre derrames vulcânicos e disjunções, são importantes para definir os locais de recarga dos aquíferos subterrâneos.

As rochas vulcânicas ácidas estão distribuídas espacialmente em relevos de blocos isolados por áreas intensamente dissecadas, geralmente no topo das elevações. Já as rochas vulcânicas básicas ocorrem em relevos profundamente dissecados, formando vales profundos e encostas em patamares que contornam os topos regionais isolando-os em blocos. A maior parte da área apresenta modelado de relevo de dissecação de intensidade moderada a forte,

A área de estudo insere-se no Bioma Mata Atlântica, com diferentes domínios fitogeográficos (Floresta Ombrófila Densa, Floresta Ombrófila Mista, Floresta Estacional Decidual, Campos de Cima da Serra).

A agricultura destaca-se pelo cultivo de soja, milho e maçã. Na pecuária, merece citação à produção de bovinos de corte e de leite e a produção de suínos e aves, sendo significante a presença de agroindústrias. De acordo com IBGE (2008), o setor econômico mais representativo é a indústria com $36,2 \%$ do PIB, seguido pelo setor de serviços com 33,6\% do PIB, e, por último, a agricultura com $30,2 \%$. Deve-se destacar o equilíbrio entre os três setores da economia, o que revela a extrema interdependência entre eles. 




Figura 2 - Localização da sub-bacia do Alto Uruguai.

\section{O AQUÍFERO SERRA GERAL}

A sub-bacia hidrográfica do Alto Uruguai insere-se na Província Hidrogeológica do Paraná, localizada na parte meridional do Brasil, correspondendo à Bacia Sedimentar do Paraná sendo preenchida por mais de $800.000 \mathrm{Km}^{2}$ de rochas vulcânicas da Formação Serra Geral. Esta Formação apresenta uma grande importância hidrogeológica, principalmente no sul do Brasil, decorrente da elevada explotabilidade das suas zonas aquíferas por meio de poços tubulares.

As rochas da Formação Serra Geral trazem características de porosidade do tipo fissural, o que permite o armazenamento de água ao longo de fraturas e descontinuidades, correspondentes às zonas vesiculares e amigdaloidais de topo de derrame e zonas de disjunção horizontal. Nanni et al, (2005) salientam que "as zonas de disjunções, quando interceptadas por fraturas ou falhas, interconectam-se e podem armazenar grandes volumes de água”.

De acordo com a Fundação Estadual de Proteção Ambiental Henrique Luiz Roessler (FEPAM, 2009), as águas subterrâneas, na Formação Serra Geral, estão condicionadas a fatores de ordem genética e tectônica. Os fatores de ordem genética são condicionantes intrínsecos da permeabilidade horizontal, ou seja, esta propriedade depende das características do material, enquanto a tectônica condiciona as permeabilidades verticais, as quais interconectam as estruturas aquíferas.

Para Costa (2008), no aquífero fissural, a porosidade é meramente função das fissuras e outras descontinuidades, não se distribuindo homogeneamente em todo o aquífero, mas variando muito, de um ponto a outro. Assim, só haverá porosidade e armazenamento de água se, em determinada zona do maciço, existir fraturas. Igualmente, a condutividade hidráulica dependerá, fundamental- 
mente, da presença de descontinuidades, já que a circulação da água no interior da rocha só ocorre através das fissuras.

Neste sentido, o aquífero Serra Geral é heterogêneo e anisotrópico, visto que a água flui com diferente velocidade para distintas direções, condicionada pelas descontinuidades sendo difícil prever a vazão. Neste sistema de fraturas, a circulação acontece quase sempre sob pressão e os poços, geralmente, apresentam um artesianismo semi-surgente (a pressão da água nas fraturas é tal que quando se perfura um poço, a água é empurrada além da superfície dando origem a poços jorrantes). As entradas de água, muitas vezes, ocorrem a partir de topos de derrame, representados por zonas amigdalares, que podem estar alteradas e intercaladas com paleosolos ou arenitos intertrápicos (FEPAM, 2009).

O sistema aquífero Serra Geral comunica-se com o aquífero Guarani (que ocorre em arenito, rocha porosa, abaixo do Serra Geral, ou em lentes entre derrames vulcânicos) através de grandes fraturas existentes no basalto. Ora o aquífero fraturado fornece água, ora recebe do aquífero poroso. Onde existe a conexão entre os dois sistemas de aqüíferos, dá-se a mistura de águas e, consequente, a alteração nos parâmetros geoquímicos. Outro ponto importante em relação à comunicação dos aquíferos diz respeito à possibilidade de contaminação do Aquífero Serra Geral através do sistema de fraturas e consequente difusão dos contaminantes para o Aquífero Guarani, que constitui uma reserva estratégica de água no Brasil Meridional. A contaminação pode fazer-se mais facilmente porque o aquífero Serra Geral é abastecido através das descontinuidades que se comportam como macroporos e não promovem uma filtragem natural da água que infiltra no interior da rocha.

\section{O PROJETO FRAG-RIO}

O Projeto Frag-Rio tem como objetivo o desenvolvimento metodológico e tecnológico para a avaliação ambiental integrada aplicada ao processo de análise da viabilidade de hidrelétricas, tendo como área de estudo a bacia hidrográfica do rio Uruguai com ênfase nas sub-bacias do Alto e Médio Rio Uruguai, localizadas nos Estados do Rio Grande do Sul e Santa Catarina.

No âmbito federal, a discussão sobre a Avaliação Ambiental Integrada iniciou;-se, em 2003, quando o Instituto Brasileiro de Meio Ambiente - IBAMA passou a exigir, no licenciamento ambiental de usinas hidrelétricas, que a bacia hidrográfica fosse considerada como área de influência dos estudos, conforme determina a Resolução do Conselho Nacional de Meio Ambiente - CONA$\mathrm{MA} \mathrm{n}^{\circ} 01 / 86$.

No início de 2004, o Ministério do Meio Ambiente - MMA começou uma série de discussões com o Ministério de Minas e Energia - MME sobre a necessidade de realização de Avaliação Ambiental Integrada de Bacia Hidrográfica como estratégia para minimizar os diversos conflitos que vinham eclodindo nos licenciamentos dos empreendimentos hidrelétricos. Esses conflitos, caracterizados por sua natureza estratégica, deveriam, em princípio, ser identificados previamente à etapa de licenciamento ambiental dos empreendimentos, de modo a favorecer a construção de soluções nas diferentes fases de sua implementação, reduzindo incertezas institucionais e de investimento.

A primeira Avaliação Ambiental Integrada, em âmbito federal, foi realizada pela Empresa de Pesquisa Energética - EPE como resultado do Termo de Compromisso firmado, em 15 de setembro de 2004, entre MME, MMA, Ibama, Advocacia Geral da União - AGU, Empresa Energética Barra Grande S.A. (BAESA) e Ministério Público Federal. Desse modo, considerando as obrigações assumidas no Termo de Compromisso de 2004 e procurando aplicar este instrumento de avaliação ambiental em outras bacias do país, o MMA assumiu a tarefa do seu aperfeiçoamento, a partir de pesquisa para o refinamento da metodologia de avaliação aplicada na bacia do Rio Uruguai, com ênfase nos seus setores mais frágeis. 
O objetivo do MMA, portanto, é estabelecer as diretrizes gerais a serem adotados pelo IBAMA nos futuros processos de licenciamento ambiental dos empreendimentos em planejamento/projeto na Bacia do Rio Uruguai, considerando as indicações derivadas dos estudos de aprimoramento metodológico da Avaliação Integrada de Bacias - AAIB da Bacia Hidrográfica do Rio Uruguai. Para cumprir este objetivo, o MMA buscou parceria com pesquisadores das Universidades Federais do Pampa - Unipampa - e de Santa Maria - UFSM, ambas no Rio Grande do Sul para realização de um projeto de pesquisa denominado Frag-Rio.

A Primeira Etapa do Projeto Frag-Rio desenvolveu-se na sub-bacia do Alto Uruguai, mais especificamente na porção da bacia em que se localizam os setores dos rios Canoas, Inhandava e Noroeste, identificados e considerados, em estudos anteriores como FEPAM/UFSM (2005) e EPE (2007) entre outros, como os mais frágeis ambientalmente, diante da implementação de empreendimentos hidrelétricos.

O objeto do projeto Frag-Rio é o estudo das fragilidades ambientais que decorrem principalmente da fragmentação da rede hidrográfica, seja por meio de barreiras físicas - devidas à implantação de empreendimentos hidrelétricos, barragens para captação de água para irrigação ou abastecimento - como pela existência de barreiras qualitativas decorrentes de alterações na qualidade da água, por lançamento de efluentes, ou por mudança do regime hídrico (de lótico para lêntico), que possam comprometer o desempenho das funções ecológicas nos cursos d'água.

No projeto Frag-Rio o termo fragilidade significa qualquer perturbação dos padrões e processos na bacia hidrográfica que pode provocar uma degradação na sua qualidade ambiental (meios terrestre e aquático, barreiras físicas ou qualitativas, permeáveis ou impermeáveis). As fragilidades são notas atribuídas para variáveis indicadoras dos processos e que podem ser mapeadas na escala do estudo.

Já o termo favorabilildade é um conceito relacionado ao empreendimento (hidrelétricas) e expressa o inverso da fragilidade. Os valores que representam baixa fragilidade possuem alta favorabilidade, enquanto que valores que representam alta fragilidade indicam baixa favorabilidade. No projeto Frag-Rio e neste artigo é utilizado o conceito de fragilidade pois está associado diretamente ao ambiente.

A metodologia utilizada, no Projeto Frag-Rio, consiste, primeiramente, na análise desagregada de blocos temáticos: Bloco Meio Físico; Bloco Meio Biótico e Bloco Meio Antrópico. Cada bloco é constituído por uma série de aspectos e estes por um número de Variáveis Indicadoras referentes a diversos temas relacionados ao próprio aspecto e ao bloco. Estas Variáveis Indicadoras combinadas, em um primeiro nível de análise, indicariam a fragilidade do Aspecto como um todo, enquanto este, por sua vez, combinado entre si gera o mapa síntese em escala 1:250.000 e indica a fragilidade do Bloco. Os blocos combinados entre si indicam os locais com maior fragilidade na sub-bacia, servindo para mostrar os trechos de rios que apresentam maior ou menor favorabilidade à implantação de usinas hidrelétricas.

No Bloco Meio Físico, foram inseridos os seguintes Aspectos: Geologia/Geomorfologia, Estabilidade de Encostas, Erosão, Áreas de Mineração e Contaminação das Águas. No Aspecto Geologia/Geomorfologia, fazem parte as variáveis: geologia/ litologia, declividade, água subterrânea (superfície potenciométrica e zona vadosa; lineamentos morfo-estruturais e lavra de água mineral) e geomorfologia.

A importância destas variáveis relaciona-se com a qualidade da rocha, a resistência ao intemperismo, a resistência mecânica associada à declividade, originando diferentes modelos de relevo, bem como a probabilidade de contaminação de aquíferos. 
A Fragilidade da variável Água Subterrânea, no Projeto Frag-Rio (2009), foi avaliada com base nos seguintes parâmetros: fragilidade da superfície potenciométrica e fragilidade da espessura da zona vadosa. Os lineamentos morfo-estruturais e as concessões de lavra de água mineral e de balneários hidrotermais foram considerados apenas como incremento da fragilidade.

Para espacializar a superfície potenciométrica da região, o Projeto Frag-Rio valeu-se de informações sobre poços tubulares e/ou escavados e nascentes cadastrados no SIAGAS/CPRM (Sistema de Informações de Águas Subterrâneas no Brasil). No Estado do Rio Grande do Sul, o cadastro contém informações de poços de diâmetro igual ou superior a $100 \mathrm{~mm}$, o que equivale a quatro polegadas (FRAG-RIO, 2009).

Segundo informações do Projeto, foram espacializados 2.623 poços cadastrados junto ao SIAGAS/CPRM na sub-bacia do Alto Uruguai, sendo que, para a simulação da superfície potenciométrica e também da zona vadosa, foram utilizados 1019 poços no Estado do Rio Grande do Sul e 1604 poços em Santa Catarina, que apresentavam informações completas. A região leste da sub-bacia apresentou grande deficiência de dados, e, por isso, recebeu valores de fragilidade elevada.

Depois de avaliados de modo individual, os parâmetros foram, posteriormente, combinados, a partir daí foram obtidos os resultados referentes à fragilidade das águas subterrâneas. Esta, por sua vez, foi combinada com as demais variáveis componentes do Aspecto Geologia/Geomorfologia, resultando na fragilidade deste Aspecto.

No projeto Frag-Rio os pesos atribuídos a cada variável foram estabelecidos com relação a sua importância e nível de discriminação dentro da sub-bacia. Desta forma, como grande parte da área é composta por rochas ígneas que apresentam excelente qualidade geomecânica e a grande maioria dos vales são encaixados (o que reduziria as áreas de alague dos empreendimentos causando menor impacto ambiental), as variáveis geologia e geomorfologia receberam peso menor do que a variável água subterrânea. Desta forma, a variável Água Subterrânea recebeu o maior peso dentre as demais, exercendo grande influência nas simulações de fragilidade para o Aspecto. O Quadro 1 apresenta os pesos atribuídos a cada variável para a obtenção do Aspecto Geologia/Geomorfologia no Projeto Frag-Rio.

Quadro 1 - Modelo para construção do Aspecto Geologia e Geomorfologia no Projeto Frag-Rio

\begin{tabular}{|l|c|}
\hline \multicolumn{1}{|c|}{ VARIÁVEL } & PESO \\
\hline Fragilidade da Geologia & 3 \\
\hline Fragilidade da Geomorfologia & 2 \\
\hline Fragilidade da Declividade & 1 \\
\hline Fragilidade da Água Subterrânea & 4 \\
\hline Total & 10 \\
\hline
\end{tabular}

Fonte: Frag-Rio, 2009.

\section{PROCEDIMENTOS METODOLÓGICOS}

Os procedimentos metodológicos empregados neste trabalho para o estabelecimento da fragilidade das águas subterrâneas na sub-bacia hidrográfica do Alto Uruguai foram baseados em uma rotina de trabalho voltada para a extração dos lineamentos estruturais do tipo 2 (AMARO; STRIEDER, 1997), a fim de determinar as suas densidades e as suas direções, parâmetros importantes para indicação da fragilidade da área.

A avaliação da fragilidade das águas subterrâneas foi realizada através da combinação de duas variáveis, que são: densidade de lineamentos e densidade de pontos de intersecção destes lineamentos (cruzamento ou contato entre planos de fraturas).As variáveis escolhidas atendem as premissas 
básicas para captação de água em aquiferos fraturados visto que a maioria dos poços produtivos nesta sub-bacia, inclusive os de água mineral e balneários hidrotermais, encontram-se em áreas de grande densidade de lineamentos e de seus cruzamentos. A extração dos lineamentos foi realizada a partir de imagens radar orbital da Shuttle Radar Topography Mission (SRTM, obtidas em http:// www.dsr.inpe.br/topodata/), pixel de 30m, com o auxílio do aplicativo Global Mapper 9.0. Os lineamentos, reconhecidos pela presença de cristas alinhadas, fundos de vale e drenagens, foram digitalizados, manualmente, diretamente na tela do monitor de vídeo, em escala aproximadamente de 1:100.000 com azimute de $45^{\circ}$.

Os lineamentos extraídos da imagem resultaram em um arquivo vetorial. Cada lineamento é representado por coordenadas UTM de seus pontos extremos (X1, Y1); (X2, Y2) o que possibilita reconhecer a sua direção e o seu comprimento. Estes dados foram exportados em formato DXF, dando suporte para a etapa de cálculo estatístico e da geração de células usadas para a determinação da densidade de lineamentos.

Para avaliação da fragilidade de um aquífero fraturado, é importante avaliar dois aspectos: densidade de fraturas ou lineamentos considerando o seu comprimento bem como a intersecção destes lineamentos. Destes dois aspectos, do ponto de vista da hidrogeologia, os pontos de intersecções dos lineamentos são os mais significativos quando se referem à recarga de aquíferos, à contaminação e à explotação de água.

Existem softwares utilizados em mineração que avaliam simultaneamente a densidade de lineamentos e a intersecção destes resultando diretamente num produto cartográfico final. Estes softwares, porém, são muito onerosos e pouco amigáveis estando disponíveis em poucos Laboratórios de Pesquisa do Brasil.

Como forma de adaptar uma metodologia que fosse mais acessível e que avaliasse estes dois parâmetros, usou-se o aplicativo ArcGis 9.3, módulo AcMap, em duas etapas: na primeira, gerou-se um mapa de densidade de lineamentos obtido pela relação entre o somatório dos comprimentos totais dos lineamentos, que ocorrem dentro de uma área circular arbitrada; na segunda, foi gerado um mapa de densidade de pontos de intersecção (zonas de cruzamento ou contato entre dois ou mais planos de fraturas) pela área circular.

Obtidos os mapas de densidade de lineamentos e densidade de pontos, o próximo passo foi à reclassificação desses documentos, estabelecendo-se notas de fragilidade que variaram de cinquenta a duzentos e cinquenta (50 - 250), pois entendeu-se que não existe área extremamente frágil a ponto de receber nota menor do que cinquenta (50) ou isenta de fragilidade com nota maior do que duzentos e cinqüenta (250). O Quadro 2 demonstra os valores de saída dos dados do aplicativo, bem como os valores usados para a reclassificação.

Posteriormente, foram atribuídos pesos para os mapas de densidade de lineamentos e densidade de pontos de intersecção. O primeiro recebeu valor $(0,30)$, enquanto o segundo recebeu $(0,70)$, haja vista que a soma das duas variáveis deve ser igual a (1). As variáveis receberam pesos diferenciados devido à influência que cada uma exerce em relação à fragilidade das águas subterrâneas. O peso maior atribuído à densidade de pontos deve-se ao fato de que os cruzamentos ou contatos entre fraturas apresentam área com dois ou mais planos de abertura na rocha, contribuindo de forma mais significativa para a percolação da água e a recarga do aquífero tendo como consequência maior fragilidade em relação à contaminação das águas subterrâneas.

A combinação dos mapas de densidade de lineamentos e densidade de pontos de intersecção resultou em um mapa síntese indicando a fragilidade da variável Água Subterrânea.

Na Segunda Fase do trabalho, combinou-se a metodologia utilizada no Projeto Frag-Rio (2009) com a metodologia desenvolvida no presente trabalho. 
NUMMER, A. V.; GUARESCHI, V. D.; SANGOI, D. S.

Quadro 2 - Valores de densidade de lineamentos e de pontos de intersecção reclassificados.

\begin{tabular}{|c|c|c|c|c|}
\hline CLAS- & \multicolumn{2}{|c|}{ RECLASSIFICAÇÃO DOS LINEAMENTOS } & \multicolumn{2}{|c|}{ RECLASSIFICAÇÃO DOS PONTOS DE INTERSECÇÃO } \\
\hline & $\begin{array}{l}\sum_{\mathrm{Km}^{2}} \text { Lineamentos }(\mathrm{m}) / \text { Área } \quad \text { em } \\
\end{array}$ & Valor reclassificado & $\begin{array}{l}\sum \text { Pontos de Intersecção/Área } \\
\mathrm{em} \mathrm{Km}^{2}\end{array}$ & Valor reclassificado \\
\hline $1^{a}$ & $0-500$ & 250 & $0-3,35$ & 250 \\
\hline $2^{\mathrm{a}}$ & $501-1500$ & 200 & $3.36-7,84$ & 200 \\
\hline $3^{\mathrm{a}}$ & $1501-3000$ & 150 & $7,85-13,67$ & 150 \\
\hline $4^{\mathrm{a}}$ & $3001-6000$ & 100 & $13,68-19,82$ & 100 \\
\hline $5^{\mathrm{a}}$ & $6001-9000$ & 50 & $19,83-28,65$ & 50 \\
\hline
\end{tabular}

Assim sendo, para avaliação do Aspecto Geologia/Geomorfologia foram combinadas novamente as diferentes variáveis, porém, no tocante às águas subterrâneas, foi utilizada a metodologia desenvolvida neste trabalho. Dessa forma, substituíram-se os parâmetros usados para caracterizar a variável Água Subterrânea, como carga potenciométrica e zona vadosa, bem como lineamentos e lavra de água mineral, pela combinação entre a densidade de lineamentos e a densidade de pontos de intersecção.

Ao rodar o novo modelo, manteve-se os mesmos pesos atribuído às variáveis pelo Projeto Frag-Rio, em que o valor mais elevado foi o da variável Água Subterrânea (Peso 4).

\section{DISCUSSÃO DOS RESULTADOS}

A partir da interpretação das imagens SRTM para a área da Sub-Bacia Hidrográfica do Alto Uruguai, foram identificados e mapeados 36.703 lineamentos estruturais conforme mostra a Figura 3.

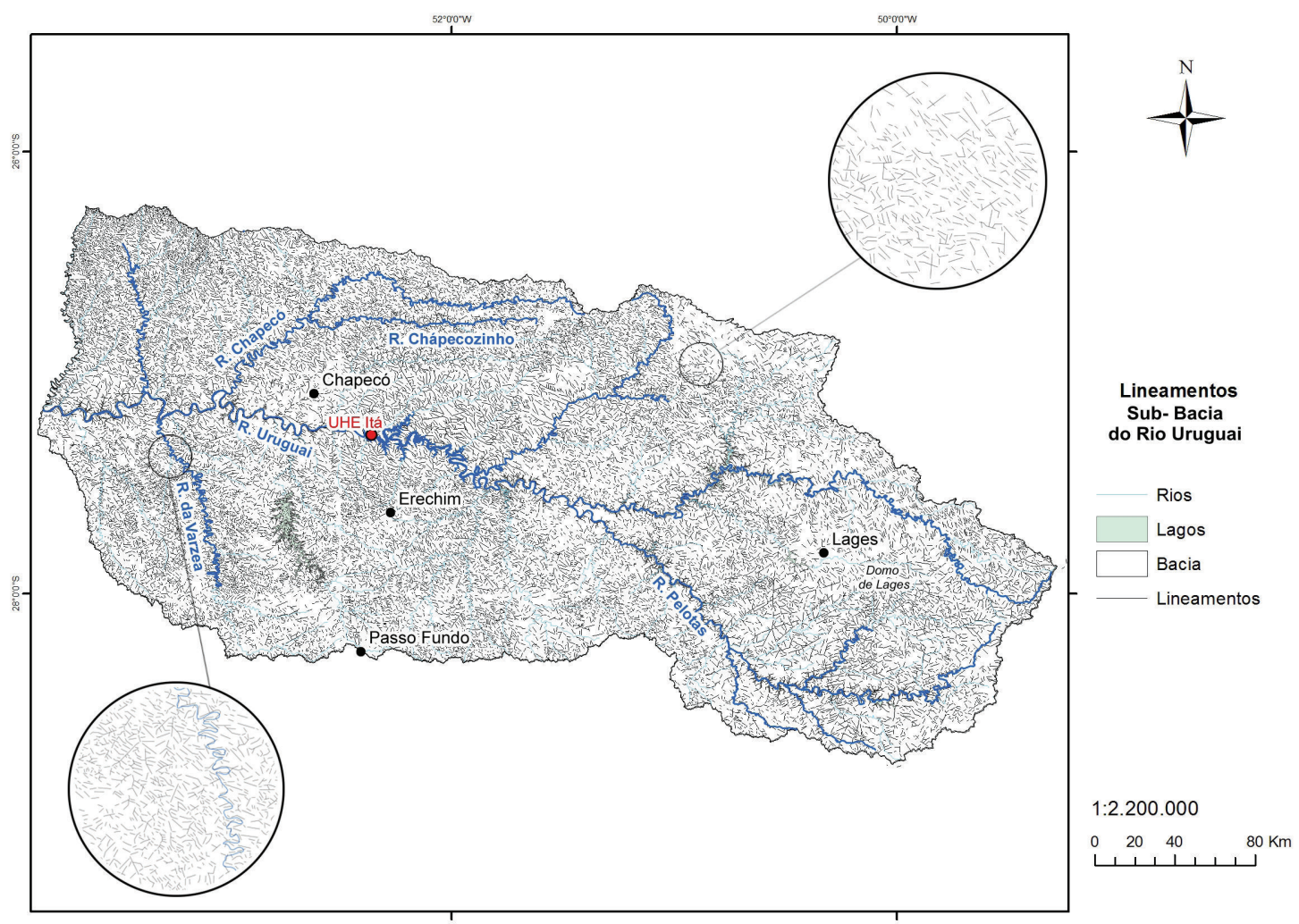

Figura 3- Mapa de lineamentos obtidos para a sub- bacia hidrográfica do Alto Uruguai. 
As maiores densidades de lineamentos encontram-se principalmente na porção sudeste, oeste e centro da bacia, próximo ao Rio Uruguai. A grande maioria dos lineamentos localiza-se segundo a direção NW-SE (Noroeste-Sudeste) variando entre $110^{\circ}$ a $160^{\circ}$ ou $290^{\circ}-340^{\circ}$ sendo que, do total mapeado, $47 \%$ estão nesta direção. Logo após, aparecem os lineamentos no sentido E-W(Leste-Oeste), representando um total de $29 \%$ dos lineamentos da bacia. Em menor número, ocorrem os de direção NE-SW(Nordeste-sudoeste) e N-S (Norte-Sul), com 16\% e 8\% do total de lineamentos, respectivamente.

Com relação aos comprimentos médios dos lineamentos, não se verifica muita diferença entre as famílias, com excessão dos lineamentos NE-SW que apresentam maior comprimento médio (2,06 $\mathrm{km}$ ), indicando a existência de extensas zonas fraturadas.

\section{Análise da fragilidade da variável água subterrânea}

Para avaliação da fragilidade da variável Água Subterrânea na Sub-Bacia do Alto Uruguai, foram elaborados dois produtos cartográficos: mapa de densidade de lineamentos ou fraturas e mapa de densidade de pontos de intersecção, representados pelo cruzamento entre planos de fraturas.

O mapa da Figura 4 mostra que as maiores fragilidades estão localizadas nas porções Sudeste, próximo ao rio Pelotas e centro da Bacia, margem direita do Rio Uruguai, nas imediações da Usina Hidrelétrica de Itá. Também ocorrem áreas de maior fragilidade na porção oeste da Bacia. As menores densidades localizam-se a leste, na região do Domo de Lajes (nos arredores do município de Lajes). Isto se deve provavelmente à presença de rochas sedimentares que, por serem consideradas mais brandas, dificultam a visualização de suas estruturas rúpteis pelas imagens SRTM.

Os locais de maior densidade de lineamento são considerados mais frágeis ambientalmente, pois facilitam a acumulação e a recarga de água subterrânea, além de refletir uma maior vulnerabilidade intrínseca do sistema aquífero. 


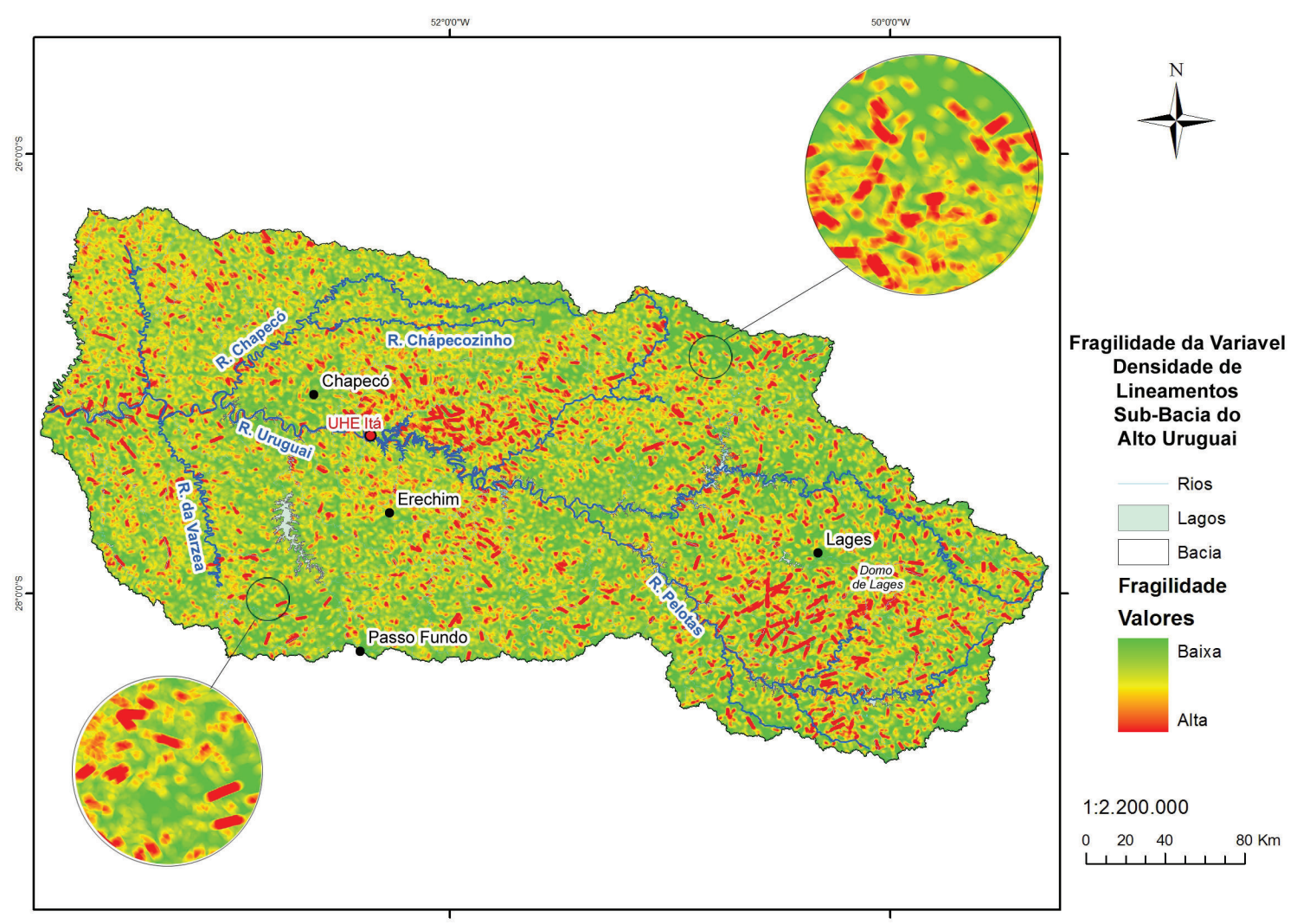

Figura 4 - Mapa de Fragilidade relativo à variável Densidade de Lineamentos ou Fraturas.

A fragilidade relativa à variável intersecção de lineamentos para a Bacia do Alto Uruguai pode ser vista na Figura 5. Analisando-se o mapa, é possível observar que as fragilidades mais elevadas são identificadas no sudoeste, noroeste, e centro-norte da bacia próximo aos Rios Chapecó e Chapecozinho e ao longo dos Rios Pelotas e Uruguai, o que torna o aquífero Serra Geral mais frágil à contaminação nestes locais.

A partir da combinação das fragilidades das variáveis densidade de lineamentos e pontos de intersecção, obteve-se um terceiro produto cartográfico contendo a fragilidade da variável Água Subterrânea para a bacia do Alto Uruguai. A Figura 6 mostra o mapa de Fragilidade relativa à variável Água Subterrânea.

É possível observar que as maiores fragilidades referentes à água subterrânea concentram-se na porção centro e oeste da bacia, especialmente no noroeste e no norte, nas calhas dos Rios Chapecó e Chapecozinho, e no centro, na margem direita do Rio Uruguai. Além destas, identificam-se áreas de alta fragilidade no extremo leste e sudeste da bacia junto ao Rio Pelotas. Nota-se a relevância dos pontos de intersecção e a significância deste parâmetro, como observado no centro norte da bacia, onde a densidade de lineamentos é baixa, mas a densidade de pontos manteve-se elevada, conferindo fragilidade alta a este setor. 

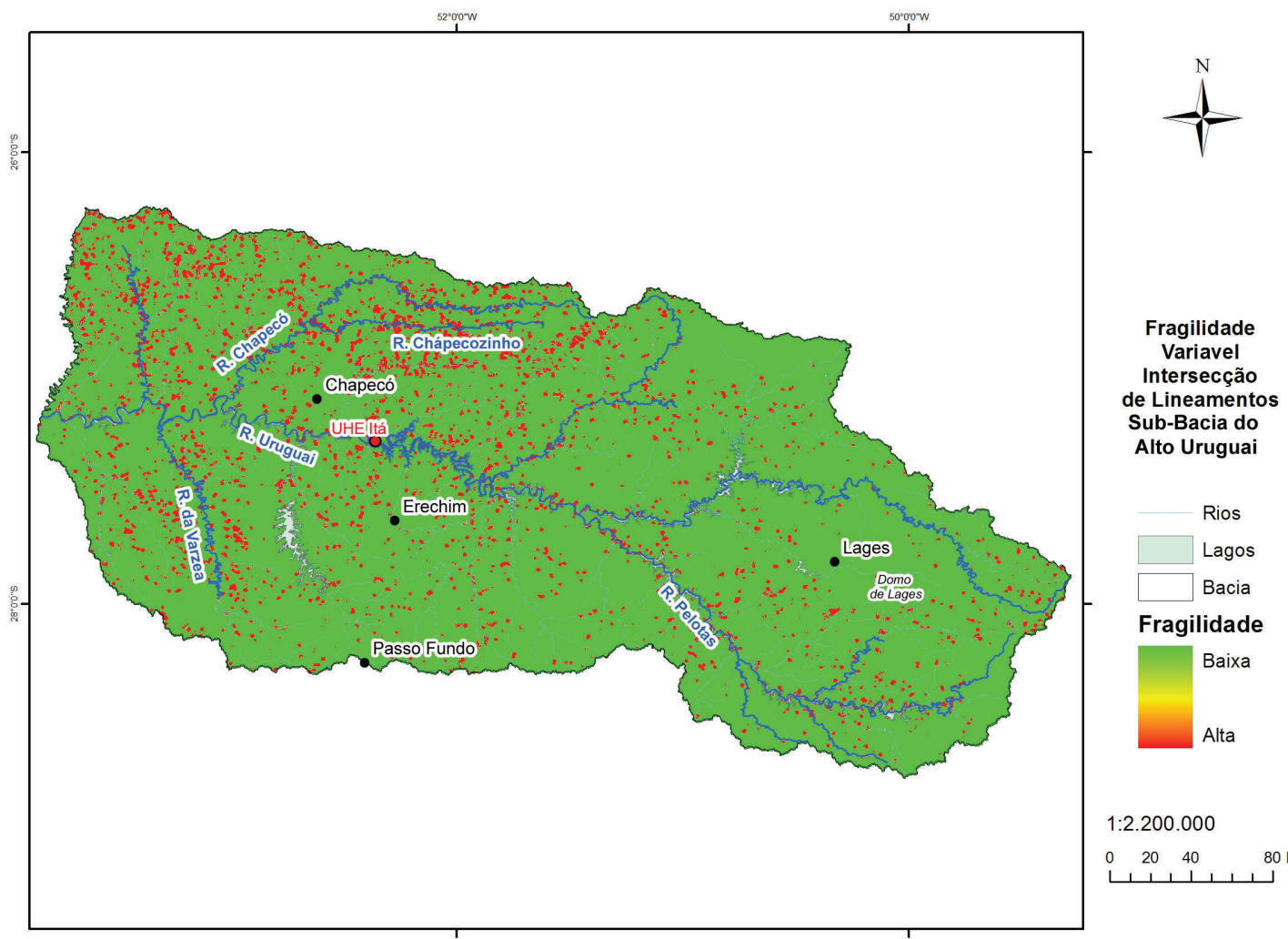

\section{Fragilidade}



$1: 2.200 .000$

$0 \quad 20 \quad 40 \quad 80 \mathrm{Km}$

Figura 5 - Fragilidade relativa à variável Intersecção de Lineamentos.

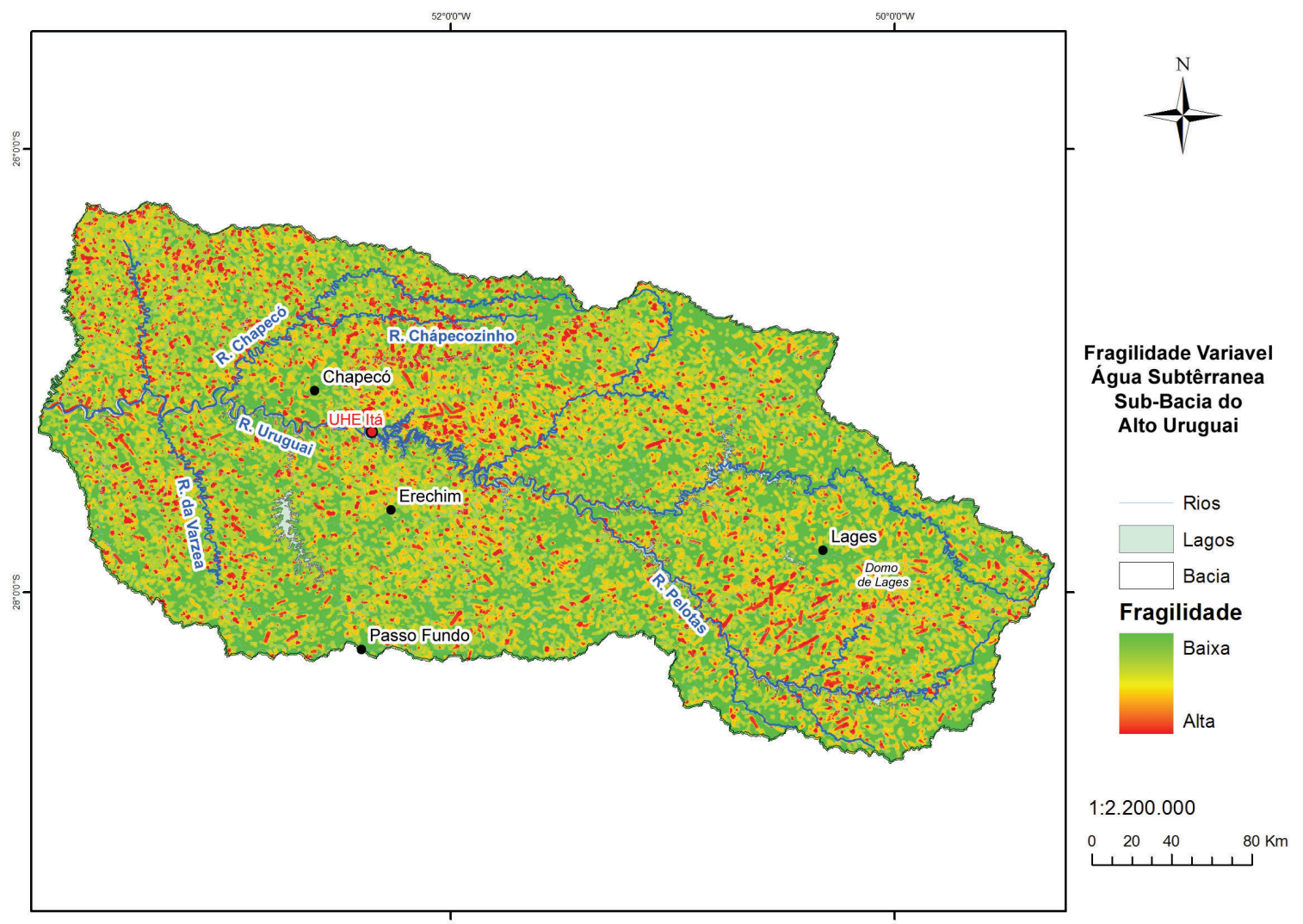

Figura 6 - Mapa de Fragilidade relativa à variável Água Subterrânea com base na densidade de lineamentos. 


\section{Comparação com os resultados obtidos no Projeto Frag-Rio}

Para a obtenção da fragilidade relativa ao aspecto água subterrânea no Projeto Frag-Rio (2009), foram trabalhadas as seguintes variáveis: espessura da zona vadosa e superfície potenciométrica, além de buffers para incremento da fragilidade ao redor dos lineamentos e dos poços de água mineral. A fragilidade da água subterrânea obtida no Projeto pode ser vista na Figura 7.

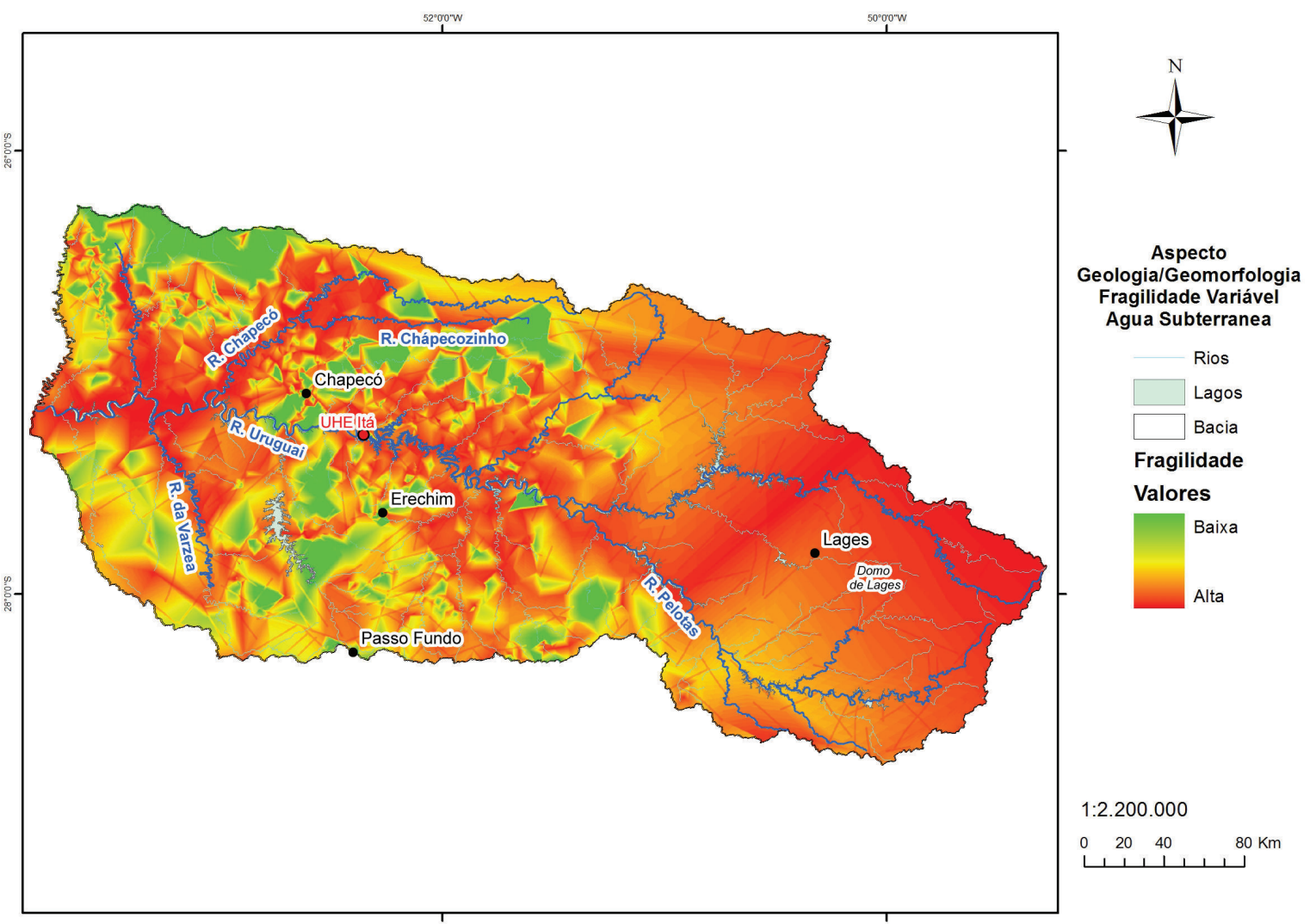

Figura 7 - Fragilidade relativa à variável Água Subterrânea obtida no Projeto Frag-Rio (2009).

As maiores fragilidades encontram-se na porção central, noroeste e oeste da Bacia. De acordo com o Relatório do Projeto, as altas fragilidades dos setores leste e nordeste devem-se ao vazio de informações sobre poços tubulares cadastrados, associando-se a isto um elevado grau de incerteza nas informações simuladas.

Verifica-se no mapa de fragilidade (Figura 6), elaborado com a metodologia de densidade de lineamentos adotada neste trabalho, que as classes de fragilidade apresentam-se mais individualizadas (fragmentadas) de forma mais heterogênea em toda a área da bacia, enquanto o mapa do Projeto Frag-Rio (Figura 7) traz áreas mais homogêneas e amplas.

As maiores diferenças são observadas na porção leste e nordeste da bacia, onde se localiza o Domo de Lajes. No mapa do Frag-Rio, essa região, como foi visto, apresentou alta fragilidade. Já no mapa elaborado para este trabalho, a porção leste e nordeste da Bacia demonstraram baixa fragilidade, por apresentarem baixa incidência de fraturas relacionadas à presença de rochas sedimentares do Domo de Lajes.

No Projeto Frag-Rio, há uma grande contribuição exercida pelo parâmetro zona vadosa para o estabelecimento da fragilidade, havendo forte correlação entre este parâmetro e a fragilidade da variável água subterrânea na bacia. Em parte, a influência limitada da superfície potenciométrica na simulação deve-se ao fato desta depender das informações sobre poços tubulares, dados que 
foram insuficientes para a porção leste da bacia, relacionando-se a isto um elevado grau de incerteza. Na metodologia adotada pelo Projeto Frag-Rio (2009), os lineamentos foram considerados apenas como incremento da fragilidade e em número muito pequeno, sem identificar os pontos de intersecção destes, fator determinante para a avaliação das fragilidades em aquíferos fraturados, como se observa na Figura 6.

Procurou-se reavaliar a fragilidade do Aspecto Geologia/Geomorfologia obtido no projeto Frag-Rio, substituindo-se a fragilidade da variável água subterrânea do projeto pela determinada neste trabalho com base na densidade de lineamentos, a fim de averiguar se esta última promoveria uma mudança considerável no resultado final da fragilidade do Aspecto.

Para isto, rodou-se novamente o modelo, mantendo-se os mesmos pesos atribuídos no Projeto às variáveis que compunham o aspecto: Geologia (3); Geomorfologia (2); Declividade (1) e Água subterrânea (4).

Como ilustra a Figura 8, no Projeto Frag-Rio, as maiores fragilidades relativas ao Aspecto Geologia/Geomorfologia estão localizadas na parte central e oeste da bacia e, a leste, junto ao Domo de Lajes. Já as menores fragilidades situam-se ao norte e no entorno do Rio Pelotas. Conforme o Projeto há uma grande influência da variável água subterrânea para a maior fragilidade encontrada na porção leste da bacia.

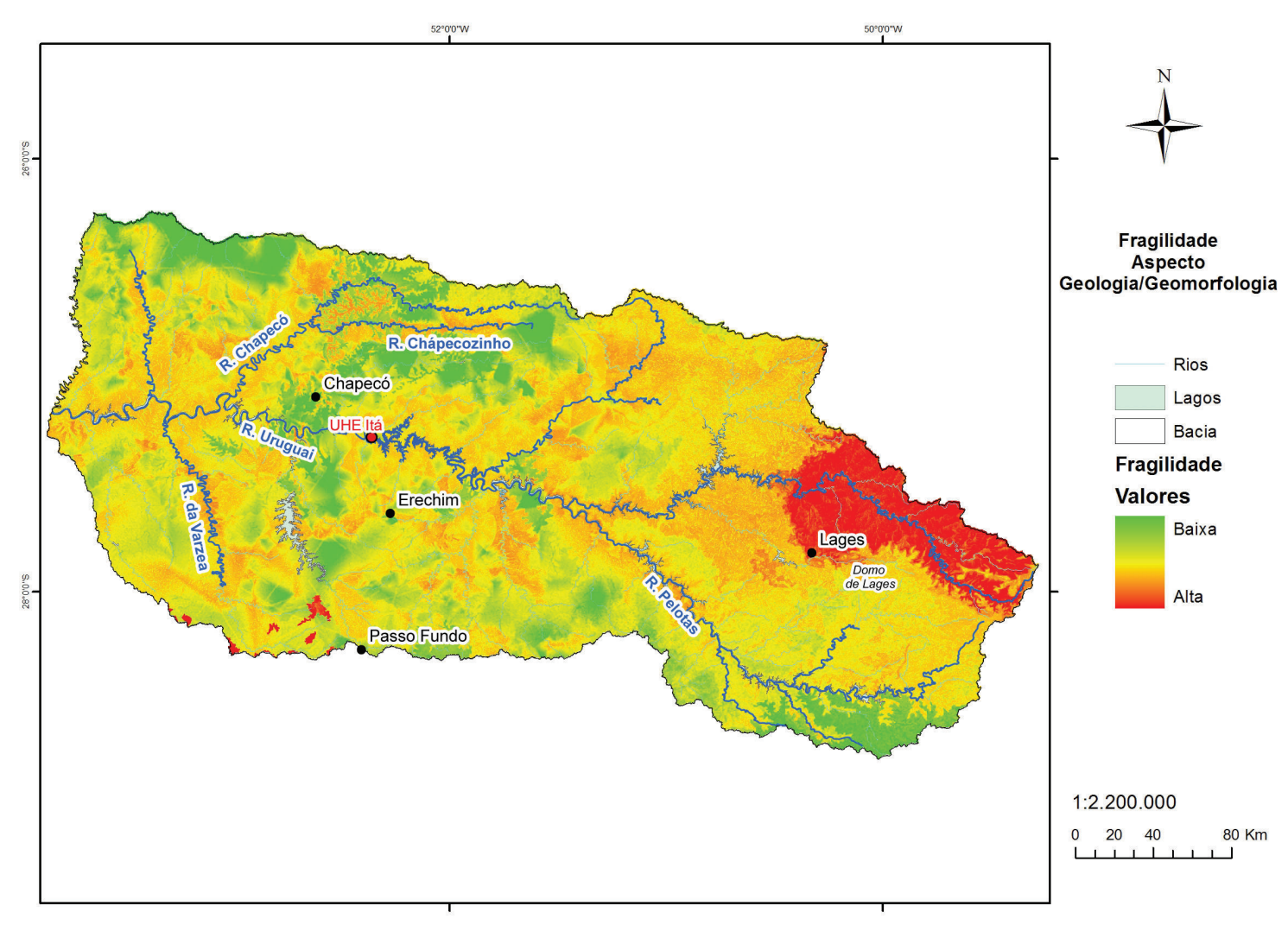

Figura 8 - Fragilidade do Aspecto Geologia/Geomorfologia obtida no Projeto Frag-Rio. Fonte: Projeto Frag-Rio (2009).

A Figura 9 mostra o mapa de fragilidade elaborado com a metodologia de densidade de lineamentos para o Aspecto Geologia/Geomorfologia. Percebe-se que ocorreu um maior detalhamento das áreas de fragilidade, muito embora elas tenham se mantido semelhantes àquelas encontradas no Frag-Rio. As maiores fragilidades também estão localizadas na porção central, noroeste e oeste da bacia bem como no leste, junto ao Domo de Lajes. 


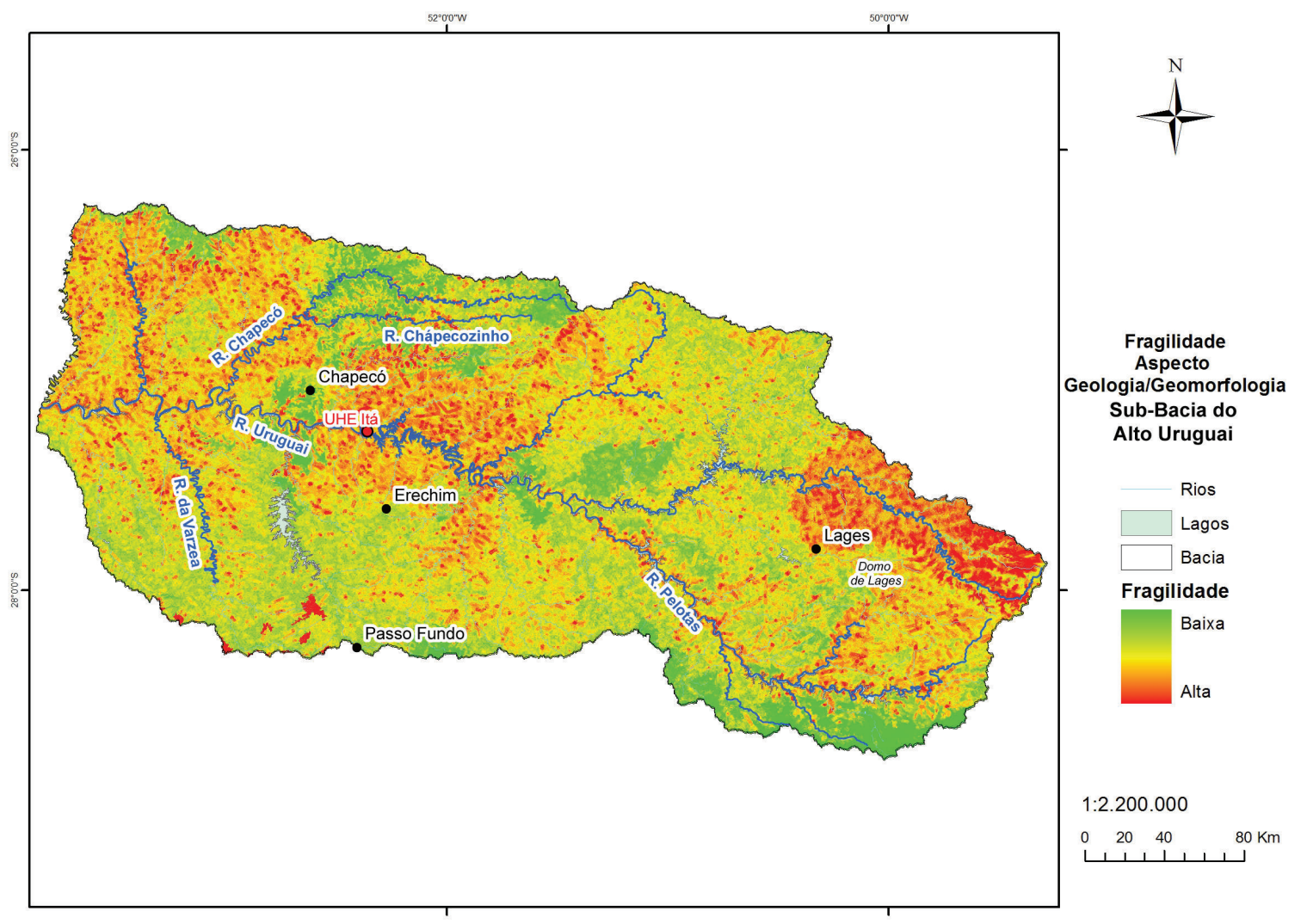

Figura 9 - Fragilidade relativa ao Aspecto Geologia/Geomorfologia.

O maior detalhamento das áreas de fragilidade deve-se à metodologia utilizada neste trabalho, que buscou mapear um grande número de lineamentos, levando em consideração o conceito referente a pontos de intersecção (cruzamentos entre planos de fraturas). Este parâmetro foi o que provavelmente mais influenciou nestes resultados.

No centro leste da bacia, as fragilidades apresentaram-se menos intensas do que no Frag-Rio. Na porção sudeste, ao longo da calha do Rio Pelotas, aparecem pequenas manchas de fragilidade que, assim como no Rio Uruguai, estão relacionadas à densidade de lineamentos e à intersecção de fraturas causada pela deformação rúptil do maciço rochoso.

Por apresentar maior detalhamento, os resultados obtidos da metodologia de densidade de lineamentos indicam a ocorrência de áreas de fragilidades menores, ou seja, mais restritas em relação ao Projeto Frag-Rio. As principais discrepâncias ocorrem no centro leste, norte e em toda a borda sul da bacia que, nas simulações, demonstraram menor fragilidade.

Grande parte do sistema aquífero da sub-bacia hidrográfica do Alto Uruguai pode ser classificado como fraturado com comportamento heterogêneo e anisotrópico, com exceção da área correspondente ao Domo de Lajes, onde o aquífero é do tipo poroso. Desta forma, considerando as características hidrodinâmicas do Sistema Serra Geral, a metodologia que adota a avaliação de densidade de fraturas é mais adequada para a avaliação da fragilidade da água subterrânea nestes locais.

A utilização das variáveis como superfície potenciométrica e espessura da zona vadosa, trabalhadas no projeto Frag-Rio, geram um grau de incerteza na abordagem desenvolvida para a avaliação da fragilidade da água subterrânea em aquíferos fraturados. Isto ocorre porque as rochas, que encerram o aquífero fissural, não apresentam porosidade como as rochas sedimentares. Neste 
sistema de aqüífero, a água é armazenada em fraturas, falhas e fissuras, com distribuição irregular e grandes variações em pequenas distâncias.

Somente haverá condutividade hidráulica em zonas onde as fraturas estão interconectadas e não se pode extrapolar esse valor para uma determinada espessura do aquífero, onde predominam zonas não fraturadas, onde a intercomunicação das fraturas se faz incipiente, ou mesmo deixa de existir. As variáveis trabalhadas no Frag-Rio poderiam ser utilizadas para a região do Domo de Lajes, em que as rochas são sedimentares e o aquífero é do tipo poroso.

\section{CONSIDERAÇÕES FINAIS}

A metodologia adotada neste trabalho procurou suprir as dificuldades de avaliação da fragilidade nos aquíferos fraturados visto que eles, segundo Costa (2008), por suas constantes descontinuidades, precária homogeneidade e forte anisotropia, não apresentam parâmetros hidrodinâmicos constantes. Para a extração dos lineamentos morfo-estruturais, utilizou-se o software Global Mapper 9.0 e as simulações de fragilidade para a variável água subterrânea foram realizadas com o auxílio do Arc Gis 9.3.

Os procedimentos metodológicos aplicados para análise da fragilidade das águas subterrâneas, nesta pesquisa, incluíram a extração de lineamentos estruturais e identificação de pontos de intersecção destes lineamentos que foram muito eficazes para a avaliação do aquífero fraturado Serra Geral na sub-bacia hidrográfica do Alto Uruguai. Os resultados mostraram alta fragilidade nas porções centro e oeste da bacia, especialmente no noroeste e no norte.

Quando comparados os mapas de fragilidade da água subterrânea do presente trabalho com os do Frag-Rio, observa-se que este estudo detalhou as áreas de fragilidades mais elevadas, enquanto que, no Frag-Rio, estas se distribuíram de forma mais homogênea em toda a extensão da bacia. Além disto, a presente metodologia acentuou a fragilidade próxima à calha dos rios, onde ocorre um grande número de intersecções de lineamentos pelo fato dos cursos d'água da região serem condicionados pela tectônica regional, o que não ficou evidente no mapa projeto Frag-Rio, em que as informações sobre a fragilidade se mostram de forma mais homogênea.

$\mathrm{Na}$ escala de trabalho adotada para os produtos cartográficos finais (1:250.000), áreas mais amplas que apresentam fragilidade elevada são aproximadamente equivalentes considerando-se ambas as metodologias. A principal diferença proporcionada pela metodologia adotada neste trabalho está na discriminação de áreas menores que apresentam fragilidade elevada, dispersas por toda a sub-bacia, o que não se observa nos mapas do Frag-Rio. Também é possível notar que o presente estudo apresenta áreas de restrição ou baixa fragilidade menores como, por exemplo, na porção leste da Bacia que, no Projeto Frag-Rio, apresentou fragilidade alta devido ao elevado grau de incerteza.

Uma das vantagens desta metodologia em relação à adotada no Frag-Rio diz respeito à acessibilidade dos dados (Imagem SRTM) e a não dependência de informações sobre poços cadastrados, fator que pode aumentar muito a incerteza do mapa de fragilidade final. Além disso, na extração dos lineamentos, tem-se a vantagem de aumentar a escala de análise sempre que se busca melhorar o nível de detalhe do mapeamento. Os pontos de intersecção de fraturas podem ser identificados na íntegra dentro da área de estudo, o que confere maior exatidão na identificação das zonas frágeis.

\section{AGRADECIMENTOS}

À FINEP pelo Financiamento do Projeto: Desenvolvimento Metodológico e Tecnológico para Avaliação Ambiental Integrada Aplicada ao Processo de Análise de Viabilidade de HidrelétricasFrag-Rio e ao CNPQ que concedeu as bolsas aos pesquisadores. 


\section{REFERÊNCIA BIBLIOGRÁFICA}

AMARO, V.E. ; STRIEDER, A.J.; Estruturas de Lineamentos Extraídos de Imagens de Sensores Remotos. EGATEA. Revista da Escola de Engenharia, Porto Alegre, v. 25, n. 4, p.109-117, julho-agosto, 1997.

BRASIL. Agencia Nacional de Energia Elétrica-ANEEL. Resolução nº 393, de 04 de dezembro de 1998. Estabelece os procedimentos gerais para registro e aprovação dos estudos de inventário hidrelétrico de bacias hidrográficas. Diário Oficial [da] República Federativa do Brasil. Poder Executivo, Brasília, DF, 04 dez. 1998. Disponível em: <http://www.zonaeletrica.com.br/legislacao/resolucoes/res_aneel/1998/98_RESOLUCAO_ANEEL_N393.pdf/>. Acesso em: 01 ago. 2009.

BRASIL. Ministério das Minas e Energia-MME. Hidreletricidade. Disponivel em: < http://www.mme.gov. br/mme/noticias/destaque2/destaque_193.html>. Acesso em: 19/10/10.

BRASIL. Instituto Nacional de Pesquisas Espaciais-INPE. SHUTTLE RADAR TOPOGRAPHY MISSION - SRTM. Disponivel em: < http://www.dsr.inpe.br/topodata/>. Acesso em: 5 de maio de 2009.

BRASIL - Conselho Nacional de Meio Ambiente-CONAMA. Resolução 01/86. Edita as regras gerais para o licenciamento ambiental de obras de grande porte, especialmente aquelas nas quais a União tenha interesse relevante, como a geração de energia elétrica. Disponível: <.http://www.mma.gov.br/port/conama/res/res86/ res0186.html>.Acesso em: 30/07/10.

CABRAL, J.S.P. Movimento das Águas Subterrâneas. In: MANOEL FILHO, J.; FEITOSA, E. C.; DEMÉTRIO, J.G.A (org). Hidrogeologia: Conceitos e Aplicações. 3 ed. Rio de Janeiro: CPRM, 2008. p. 121-151.

COSTA, W. D. Hidrogeologia dos Meios Fissurados. In: MANOEL FILHO, J.; FEITOSA, E. C.; DEMÉTRIO, J.G.A (org). Hidrogeologia: Conceitos e Aplicações. 3 ed. Rio de Janeiro: CPRM, 2008. p. 121-151.

EPE. Empresa de Pesquisa Energética. Avaliação Ambiental Integrada (AAI) dos Aproveitamentos Hidrelétricos da Bacia Hidrográfica do Rio Uruguai. Relatório Final. Brasília: Consórcio Themag/Andrade \& Canellas/Bourscheid, 2007. 437p.

FEPAM. Fundação Estadual de Proteção Ambiental Henrique Luis Roesller-FEPAM. Avaliação qualitativa da Disponibilidade hídrica subterrânea. Disponível em: <http://eta.fepam.rs.gov.br:81/documentacoes/ uruguai/relatorio02/Cap\%206.pdf>. Acesso em: 05 ago. 2009.

FEPAM. Fundação Estadual de Proteção Ambiental Henrique Luiz Roessler e UFSM. Universidade Federal de Santa Maria. Análise de Fragilidades Ambientais da Bacia Hidrográfica dos rios Apuaê-Inhandava, situada na Região Hidrográfica do rio Uruguai. Relatório Técnico Final. Santa Maria: FEPAM/UFSM, 2005. 86p.

FRAG - RIO. UNIVERSIDADE FEDERAL DE SANTA MARIA. Desenvolvimento Metodológico e Tecnológico para Avaliação Ambiental Integrada Aplicada ao Processo de Análise de Viabilidade de Hidrelétricas- Etapa 1. Relatório Técnico. REF 037408. Santa Maria, Mar. 2009. 296p.

IBGE. Instituto Brasileiro de Geografia e Estatística. Censo Demográfico 1991. População Residente Urbana e Rural. Disponível em ftp://ftp.ibge.gov.br/Censos/Censo_Demografico_1991/Populacao_Residente_Urbana_Rural/Rio_Grande_do_Sul.zip Acesso em 28/10/2008.

MANOEL FILHO, J. Ocorrência das Águas Subterrâneas. In: FEITOSA, F. A. C. ., MANOEL FILHO, J.; FEITOSA, E. C.; DEMÉTRIO, J.G.A (org). Hidrogeologia: Conceitos e Aplicações. 3.ed. Rio de Janeiro: CPRM, 2008. p. 53-75.

MARQUES, Maria Madalena S. A identidade água abaixo: os reassentados da usina hidrelétrica Dona Francisca/RS-Brasil. 2005.115f. Dissertação (Mestrado em Extensão Rural). Santa Maria: Universidade Federal de Santa Maria, Santa Maria,2005.

NANNI, A. S.; TEDESCO, M, A.; FREITAS, M, A.;BINOTTO, R, B.Vulnerabilidade natural e risco de contaminação do Aquífero Serra Geral pela suinocultura na região das Missões - RS. In: SIMPÓSIO BRASILEIRO DE. RECURSOS HÍDRICOS, 16., 2005, João Pessoa. Anais... João Pessoa: SBRH, 2005. Disponível em: < http://www.dpi.inpe.br/spring/portugues/arquivos_publicacoes/xvi_sbrh.pdf $>$. Acesso em: 28 set. 2009. 
NIMMER, E. Climatologia do Brasil. 2. ed . Rio de Janeiro: IBGE. 1989.421p.

RADAMBRASIL - Levantamento de Recursos Naturais, folha SH.22 Porto Alegre e parte das Folhas SH.21 Uruguaiana e SI.22 Lagoa Mirim. Rio de Janeiro: Fundação Instituto Brasileiro de Geografia e Estatística-IBGE,1986 v.33.

Trabalho enviado em novembro de 2011

Trabalho aceito em dezembro de 2011 